\title{
Biochemical Treatment and Utilization of Fecal Wastewater
}

\author{
Haiyan Hu, Xin Zhou \\ Marine Science and Technology College, Zhejiang Ocean University, Zhoushan, China \\ Email: queencrab@163.com
}

How to cite this paper: Hu, H.Y. and Zhou, X. (2020) Biochemical Treatment and Utilization of Fecal Wastewater. Open Access Library Journal, 7: e6315. https://doi.org/10.4236/oalib.1106315

Received: April 11, 2020

Accepted: November 22, 2020

Published: November 25, 2020

Copyright $\odot 2020$ by author(s) and Open Access Library Inc.

This work is licensed under the Creative Commons Attribution International License (CC BY 4.0).

http://creativecommons.org/licenses/by/4.0/

\section{(c) (i) Open Access}

\begin{abstract}
In order to treat and utilize urban fecal wastewater more effectively, a process for biochemical treatment of fecal wastewater from urban settlements was established in this study. After treating the fecal wastewater collected, solid and liquid organic fertilizers can be obtained. Compared to the commercially available urea, the solid organic fertilizer can increase the yield of okra by $12.89 \%$ at podding stage, while the liquid organic fertilizer can prolong the flowering period of Chinese orchid by 3 - 4 days compared to the untreated urine. Gases generated by various processing units are all collected to the biological deodorization system for treatment, which have no significant odor after treating through the system. The water outlet from the water reclamation system meets the national quality standards for urban miscellaneous water under urban wastewater reclamation and reuse.
\end{abstract}

\section{Subject Areas}

Environmental Sciences

\section{Keywords}

Fecal Disposal, Biochemical Treatment, Green Organic Fertilizer, Wastewater Reuse

\section{Introduction}

Feces and urine, as physiological excrements of human digestive and urinary systems, are rich in organic matters, nitrogen, phosphorus and potassium, which are traditional organic agricultural fertilizers and good soil conditioners. Although their mixture is often used as manure, they are applied directly to farmlands or discharged in most cases without going through sanitary collection and harmless disposal, not only affecting crop absorption and seriously deteriorating 
surrounding environment, but also leading to the spread of diseases. If organic matters, nitrogen, phosphorus and the like in feces are discharged directly, they will cause water pollution and emit harmful gases containing ammonia, hydrogen sulfide, mercaptan, thioether and other malodorous components [1]. Patients' stool also contains a variety of intestinal pathogenic bacteria, parasitic ova and viruses. According to statistics, about $70 \%$ of diseases in developing countries are associated with biological fecal infection. Among causes of the above situations, outdated collection and transportation methods of feces and urine and backward utilization technology are the two crucial causes. Currently, the following problems exist in the disposal of urban household feces-urine mixture in China:

1) Simple treatment and disposal methods

In China, feces and urine have a long history of use as fertilizer sources and soil conditioners. For a long time, people have focused more on their utilization as resources while giving little consideration to their pollution hazards [2]. Fecal treatment has not received adequate attention. Some fecal wastewaters are not gone through disinfection and sterilization, which are used for irrigating crops even though they cannot meet hygienic standards; some other fecal wastewaters are directly discharged into rivers via the pipeline, thereby threatening human health and affecting living environments. Septic tank was once the main means of disposing urban fecal and urinary wastes, but most septic tanks failed to regularly clean up, and were even in the long-term unclean state. Prolonged accumulation of fecal sludge without cleaning up causes fecal residue compaction, making the septic tanks practically functionless. Lack of effective harmless treatment of feces leads to water contamination. Besides, bombing incidents caused by septic tanks are also often reported.

2) Indiscriminate application of treatment processes

With the progression of urbanization, most of China's medium-sized cities have built sewage treatment plants, refuse landfills and other municipal sanitation facilities. Cities are blindly following suit in the selection of fecal treatment processes, without researching or analyzing inter-city differences and their respective characteristics. For example, some cities have adopted "pretreatment + sewage treatment plant" two-level fecal treatment process, but have not done sufficient research on the operation of domestic sewage treatment plants that receive fecal filtrate or on the water quality. Concentration of fecal filtrate is still too high even after the operation of fecal treatment plants; thus leading corresponding sewage treatment plants cannot meet the treatment standards, which is not only a waste of resources, but also increases investment and operating costs [3].

3) Lack of research on scale and layout relationships between fecal treatment sites and corresponding sewage treatment plants

In addition to the process-level blind following, there also lacks research on the scale and layout relationships between fecal treatment sites and corresponding sewage treatment plants. Due to the hasty implementation of centralized ur- 
ban fecal treatment project resulted from civilized city rating and many other factors, necessary research on the scale, layout and treatment process of existing sewage treatment plants and refuse landfills are lacking, leading urban sewage treatment plants either overly high loaded and unable to meet treatment standards, or insufficiently loaded and face difficulties in operation [4].

4) Prominent shortcomings of old operational mode, incomplete policies and relevant regulations

Former mode of separated management of fecal treatment and sewage treatment by environmental sanitation department and municipal administration department attributed to government system has not only restricted fecal treatment, but also affected sewage treatment and comprehensive utilization of sanitation and municipal facilities, with a certain waste of funds. Fecal treatment is currently still mainly managed by government departments. Government lacks funds, while private capital is active. Relevant policies and regulations on the marketization process of fecal treatment are lacking. Specifications for Design of Urban Fecal Treatment Plants (Sites) CJJ64-95 promulgated in 1995 by the State Ministry of Construction can no longer keep up with the rapid urban development. A number of new treatment facilities using new treatment technologies have no standards to follow [2] [3] [4].

Therefore, disposal of urban and rural feces in accordance with the principles of reduction, harmlessness and utilization has important practical significance [5] [6] [7]. This study turns urban fecal and urinary wastes into green fertilizers through a biochemical treatment process to achieve harmless treatment of urban fecal wastes, which also helps gain some economic value as well.

\section{Material and Methods}

\subsection{Material and Bacteria}

Feces and urine were collected from the urban fecal treatment site, whose water content was $80 \%$ by preliminary test. Meanwhile, surrounding soil was collected for screening of dominant bacteria. After isolation and screening of dominant microflora and through repeated combinations of multiple bacteria, abnormal odorless, secondary pollution-free compound bacterial agent that could rapidly degrade organic matters was obtained eventually. Previous experiments have demonstrated that the compound bacteria had an organic matter degradation rate of over 90\%; could well grow and react biochemically in low, moderate and high temperature environments to complete rapid degradation of complex organic substances; had strong applicability to acids, alkalis and salts; had a bacterial content in the agent $\geq 6 \times 10^{9} / \mathrm{g}$; and had strong regeneration capability, without needing long-term dosing. CAS Institute of Microbiology identified it as follows: the compound bacterial agent does no harm to the individual, group health or the ecological environment, which has stable genetic properties and a safety grade of I. Shanghai Institute of Preventive Medicine's test findings: acute oral toxicity test: mice LD50 > $10.0 \mathrm{~g} / \mathrm{kg}$; skin irritation test: nonirritant; micronucleus test: negative. Deodorization system used the commercially available 
autotrophic sulfur-oxidizing bacteria [8].

\subsection{Design of Biochemical Fecal Wastewater Treatment Process}

The process flow designed in this study for biochemical fecal wastewater treatment is shown in Figure 1. Feces was inoculated with bacterial agent, and biochemical process and microbial technology were utilized to allow beneficial microorganisms to reproduce rapidly and quickly decompose organic matters in feces and mixture, and to rise the pile temperature to $60^{\circ} \mathrm{C}-70^{\circ} \mathrm{C}$ in a short time, thereby inhibiting or killing germs and eggs. Meanwhile, mineralization and humification could absorb and decompose malodors and harmful substances, and release active trace elements such as nitrogen, phosphorus and potassium. After thorough decomposition by biological fermentation, feces was dried with rotating hot air and pelletized to become harmless, odorless quality solid organic fertilizer. Liquid portion of the solid-liquid separation system was passed through biological anaerobic system to produce biogas, and then the outlet water was turned into liquid organic fertilizer by microbial technology (MBR: Membrane Bio-Reactor). This liquid organic fertilizer was pumped to the organic farmlands to provide natural, good organic fertilizer for organic agriculture. Functional flora and their bioenzyme secretions, as well as high-molecular compounds in organic wastes such as celluloses, proteins and fats were converted to various low-molecular substances like $\mathrm{CO}_{2}, \mathrm{NH}_{3}$, alcohols and organic acids through a complex series of biochemical reactions. These substances were then decomposed and completely evaporated and discharged from the processor, eventually leaving over non-toxic, odorless fertilizer rich in a variety of nutrients. Gases generated by various units were all collected to the biological deodorization system. Polyester fiber biofiller balls with large specific surface area were selected as the carrier of deodorant microorganisms, and malodorous molecules were removed by aerobic microbial adsorption.

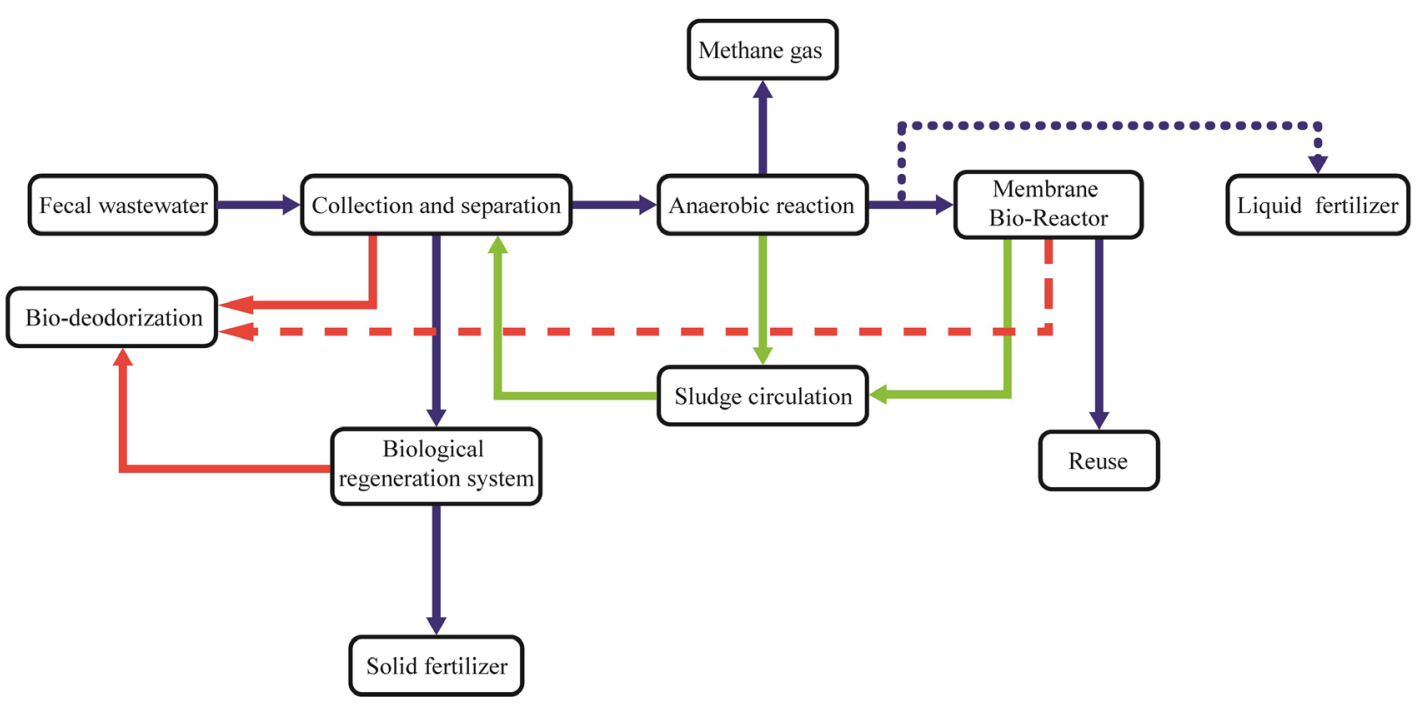

Figure 1. Process flow of biochemical fecal wastewater treatment. 


\subsection{Inspection and Description of Organic Fertilizer Properties [9] [10] [11]}

Organic fertilizer components were inspected based on the method stipulated in the GB 15063-2001 Compound fertilizer, while components of liquid organic fertilizer were inspected according to the method recommended in the Zhejiang Provincial criteria DB33/699-2008 "Safety requirements for organic liquid fertilizer and organic-inorganic compound liquid fertilizer".

Fertilizer efficiency inspection: Before podding stage, two groups (100 plants/group) of okras were applied separately with the commercially obtained urea fertilizer and the solid organic fertilizer produced herein at $20 \mathrm{~g} / \mathrm{plant}$, and irrigated with the same sufficient amount of water once every three days. 21 days later, yields were examined by weighing.

Two groups (50 plants/group) of Chinese orchids in near flowering period were added separately with the ordinary urine and the liquid organic fertilizer produced herein at $50 \mathrm{ml} /$ plant, irrigated with the same sufficient amount of water every day, and recorded for length of flowering period.

\subsection{Design of Water Reclamation System Process}

Although water reclamation is an auxiliary system for utilization of fecal wastewater, it is also very important. Anaerobic water left over from the fecal biochemical treatment process which could not be completely utilized was treated and reclaimed for landscape irrigation, toilet flushing and fish culture. The main treatment process flow is shown in Figure 2. Quality of outlet water was inspected according to the National quality standards for urban miscellaneous water under urban wastewater reclamation and reuse (GB/T18920-2002).

Grating well with rotating drum grids was established for removing floating matters, high density household garbage and larger particles in the wastewater, in order to protect the devices used for subsequent processes. To better remove the grits in the fecal wastewater and to prevent smaller-sized grits from accumulating in subsequent processing systems, a grit chamber was set up. Sediments in the chamber bottom were transferred outward by the screw conveyor system. Solid-liquid separation tank was located in the front end of processing structures. Fecal wastewater was stayed in the collection tank for no longer than $36 \mathrm{~h}$. Feces and other suspended impurities in the wastewater were intercepted and separated by collection tank, then pumped to the biorenewable resource conversion system. Wastewater was preliminarily treated by anaerobic decomposition. To ensure the continuity and stability of subsequent wastewater treatment and to reduce the subsequent treatment burden, adjusting tank was set up. The tank had a reinforced concrete structure, which could block large amounts of suspended solids. The wastewater in the buffer tank was pump lifted into the reaction tank. Outlet water from the solid-liquid separation tank still contained suspended solids. Separate dosing of coagulant and flocculant in the reaction tank could remove large amount of SS. Precipitated sludge was pumped to the sludge 


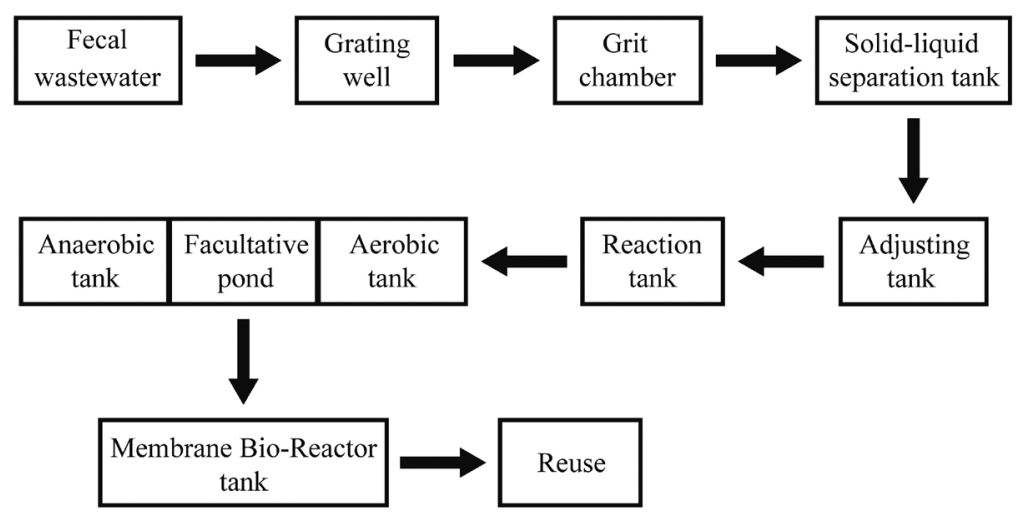

Figure 2. Water reclamation system process.

storage tank, centrifuged and ultimately transferred outward. Anaerobic treatment was an effective way of removing organic contaminants and mineralizing them. Functional bacteria degraded organic macromolecules into small molecular substances while producing biogas during the process. Its main advantages were: significantly reduced energy demand; small sludge production; good sedimentation; capability of treating substances non-biodegradable to conventional organisms by function bacteria contained in the tank; wide adaptability to water temperature; high organic volumetric loading rate; and low demand for nutrients. Water treated by the aerobic process still contained high concentrations of ammonia nitrogen. Establishment of an A/O treatment system could allow nitrification and denitrification of ammonia nitrogen, and thus enhance the ammonia-nitrogen removal in the system. Biological tank was equipped with aeration tube, where aerobic aeration was employed. Under aerobic conditions, phosphorus bacteria grew actively, which substantially absorbed free phosphorus in the wastewater to let it become an important constituent of cells, and then discharged with the sludge, thereby achieving phosphorus removal. Wastewater purified through the aeration tank had a $\mathrm{BOD}_{5}$ removal rate of over $95 \%$ [12]-[18].

\section{Results and Discussions}

\subsection{Production and Efficiency of Solid Organic Fertilizer}

Percentage of dry matters in the fecal wastewater was low, which was generally around $2 \%$. These dry matters contained large amounts of nitrogen and phosphorus, which were ideal organic fertilizer. Fertilizer production level in the biorenewable resource conversion system was $5-7 \mathrm{~kg}$ of dry matters per day. In the fertilizer processing equipment, dry matters were eventually converted into nitrogen- and phosphorus-rich semi-finished organic fertilizer by the functional bacteria added at an appropriate temperature. The organic fertilizer was loose and odorless, which can be used as base fertilizer in the organic farmlands and can also be quantitatively input into the pelletization system to produce organic fertilizer. Its main components are shown in Table 1. 
Table 1. Main components of solid organic fertilizer.

\begin{tabular}{cccccccc}
\hline $\mathrm{pH}$ & $\mathrm{TN}$ & Nitrate & Ammonia & Organics & $\mathrm{TP}$ & $\mathrm{AP}$ & $\mathrm{AK}$ \\
\hline-- & $\%$ & $\mathrm{mg} / \mathrm{kg}$ & $\mathrm{mg} / \mathrm{kg}$ & $\%$ & $\mathrm{mg} / \mathrm{kg}$ & $\mathrm{mg} / \mathrm{kg}$ & $\mathrm{mg} / \mathrm{kg}$ \\
\hline $7.86-7.95$ & $49.4-56.2$ & $6.90-7.03$ & $12.3-12.8$ & $86.6-87.9$ & $3452-3467$ & $297-301$ & $1350-1371$ \\
\hline
\end{tabular}

On June 7, 2018, before podding stage, 200 okras were applied separately with the commercially obtained urea fertilizer and the solid organic fertilizer produced in this study. 21 days later, yields were examined. On June 29, 2018, the average yields at harvest were $2.87 \mathrm{~kg} /$ plant and $3.24 \mathrm{~kg} /$ plant, respectively, demonstrating a mean yield increase of $12.89 \%$. The solid organic fertilizer produced herein was distinctly superior to the ordinary urea.

\subsection{Liquid Organic Fertilizer}

Addition of functional bacteria to the outlet water after anaerobic decomposition could enable efficient, rapid conversion of fecal water, without odor or secondary pollution during the conversion process, which allows high elimination rate as well. Functional bacteria could well grow and react biochemically in all of low, moderate and high temperature environments to complete rapid degradation of complex organic substances, thereby achieving fecal recycling and utilization. Laboratory test of the indices of the liquid fertilizer were displayed in Table 2.

Analysis of fertilizer efficiency found that the liquid organic fertilizer converted with functional bacterial which was a good natural organic fertilizer, was in line with the National Standards for Efficiency of Organic Fertilizers (NY525-2002). On April 1, two groups (50 plants/group) of Chinese orchids in near flowering period were added separately with the ordinary urine and the liquid organic fertilizer produced herein at $50 \mathrm{ml} / \mathrm{plant}$, and recorded for length of flowering period. And the results showed that the liquid organic fertilizer could prolong the flowering period of Chinese orchid by $3-4$ days compared to the untreated urine.

\subsection{Water Reclamation}

Water quality of the water reclamation system was detected for 8 consecutive months From May to December of 2015. Main water quality status is shown in Table 3. The results revealed that after treatment by the water reclamation system, the anaerobic water from the biochemical fecal wastewater treatment system had quality indices meeting the national quality standards for urban miscellaneous water under urban wastewater reclamation and reuse.

\subsection{Biological Deodorization System}

The essence of biological deodorization process was to utilize microbial life activities to convert odor-producing substances in the air into simple odorless 
Table 2. Indices of the liquid fertilizer.

\begin{tabular}{cccccc}
\hline $\mathrm{pH}$ & Water & Organics & $\mathrm{COD}$ & Ammonia & $\mathrm{TP}$ \\
\hline & $\%$ & $\%$ & $\mathrm{mg} / \mathrm{L}$ & $\mathrm{mg} / \mathrm{L}$ & $\mathrm{mg} / \mathrm{L}$ \\
\hline $6.5-6.7$ & $20-25$ & $46.4-49.1$ & $405-892$ & $579-817$ & $207-598$ \\
\hline
\end{tabular}

Table 3. Average water quality of reclamation system outlet.

\begin{tabular}{ccccc}
\hline \multirow{2}{*}{ Time } & DO & & Escherichia coli biomass & \multirow{2}{*}{ Chroma } \\
\cline { 2 - 3 } & $\mathrm{mg} / \mathrm{L}$ & & cell/L & 20 \\
May & 2.0 & 6.8 & 1 & 15 \\
June & 2.5 & 6.6 & 0 & 5 \\
July & 2.4 & 6.7 & 0 & 15 \\
August & 2.5 & 6.8 & 0 & 15 \\
September & 2.8 & 6.8 & 2 & 6 \\
October & 3.9 & 7.3 & 0 & 5 \\
November & 3.4 & 6.9 & 0 & 5 \\
December & 2.3 & 6.5 & 0 & 5 \\
\hline
\end{tabular}

substances (i.e. carbon dioxide, water, inorganic salts, etc.), less odorous components with high olfactory thresholds and cytoplasm to achieve deodorization purpose.

When the malodorous $\mathrm{H}_{2} \mathrm{~S}$ gas entered the device, obligate autotrophic sulfur-oxidizing bacteria would oxidize $\mathrm{H}_{2} \mathrm{~S}$ into sulfate radicals under certain conditions (elemental sulfur in some cases). Where the malodorous gas was organic sulfurs such as methyl mercaptan, conversion of organic sulfur to $\mathrm{H}_{2} \mathrm{~S}$ by heterotrophic microbes was needed first, then the $\mathrm{H}_{2} \mathrm{~S}$ would be oxidized by autotrophic microbes into sulfate radicals. Reaction formulas are shown below.

$\mathrm{H}_{2} \mathrm{~S}+\mathrm{O}_{2}+$ Autotrophic sulfur-oxidizing bacteria $+\mathrm{CO}_{2} \rightarrow$ Synthesized cellular material $+\mathrm{SO}_{4}^{2-}+\mathrm{H}_{2} \mathrm{O}$

$$
\mathrm{CH}_{3} \mathrm{SH} \rightarrow \mathrm{CH}_{4}+\mathrm{H}_{2} \mathrm{~S} \rightarrow \mathrm{CO}_{2}+\mathrm{H}_{2} \mathrm{O}+\mathrm{SO}_{4}^{2-}
$$

Other non-sulfur-containing organic malodorous gas components were converted to $\mathrm{CO}_{2}$, water or nitrates in the liquid or biological phase, and were partially assimilated by microbes and converted into biomass. Compared to the conventional adsorption, absorption and incineration methods, biological treatment had advantages like low operational costs and no secondary pollution.

\section{Conclusion}

In this study, a process for biochemical treatment of fecal wastewater from urban settlements is established. After treating the fecal wastewater collected, solid and liquid organic fertilizers can be obtained. Compared to the commercially available urea, the solid organic fertilizer can increase the yield of okra by $12.89 \%$ at podding stage, while the liquid organic fertilizer can prolong the flo- 
wering period of Chinese orchid by 3 - 4 days compared to the untreated urine. Gases generated by various processing units are all collected to the biological deodorization system for treatment, which have no significant odor after treating through the system. The water outlet from the water reclamation system meets the national quality standards for urban miscellaneous water under urban wastewater reclamation and reuse. The harmless biochemical fecal recycling technology has obvious advantages compared to the existing fecal wastewater treatment methods in terms of sustainable development. The urban fecal wastewater treated meets the hygienic indices for harmless disposal, thus eliminating the vicious cycle of fecal pathogens, effectively controlling their contamination of urban water environment, and reducing the burden on urban sewage treatment plants, which is of important practical significance for energy conservation, emission reduction, as well as construction of resource-saving, environment-friendly society.

\section{Acknowledgements}

This study was supported by Basic public welfare projects in Zhejiang Province (No. LGF18D060001).

\section{Conflicts of Interest}

The authors declare no conflicts of interest regarding the publication of this paper.

\section{References}

[1] Ohkuma, N., Shinoda, T., Aoi, T., Okaniwa, Y. and Magara, Y. (1994) Performance of Rotary Disk Modules in Collected Human Excreta Treatment Plant. Water Science \& Technology, 30, 141-149. https://doi.org/10.2166/wst.1994.0178

[2] Xiong, H.-B., Zhang, Z. and Gu, L.-P. (2009) Influence of Centralized Treatment of Urban Excrement on Wastewater Treatment Plant. China Water \& Wastewater, 25, 17-21.

[3] Jang, A., Yoon, Y.H., Kim, S.L., et al. (2003) Characterization and Evaluation of Aerobic Granules in Sequencing Batch Reactor. Journal of Biotechnology, 105, 71-82. https://doi.org/10.1016/S0168-1656(03)00142-1

[4] Hu, L.L., Wang, J.L., Xiang, H., et al. (2005) Study on Performance Characteristics of SBR under Limited Dissolved Oxygen. Process Biochemistry, 40, 293-296. https://doi.org/10.1016/j.procbio.2004.01.015

[5] Cofie, O. (2009) Co-Composting of Faecal Sludge and Organic Solid Waste for Agriculture: Process Dynamics. Water Research, 43, 4665-4675. https://doi.org/10.1016/j.watres.2009.07.021

[6] Kurup, B. (2002) Co-Treatment of Septage in a Municipal Sewage Treatment Pond System. Water Science and Technology, 46, 315-321. https://doi.org/10.2166/wst.2002.0268

[7] Redlinger, T., et al. (2001) Survival of Fecal Coliforms in Dry-Composting Toilets. Applied \& Environmental Microbiology, 67, 4036-4040. https://doi.org/10.1128/AEM.67.9.4036-4040.2001 
[8] National Quality Standards for Urban Miscellaneous Water under Urban Wastewater Reclamation and Reuse, GB/T18920-2002, China.

[9] Compound Fertilizer, GB 15063-2001, China.

[10] Safety Requirements for Organic Liquid Fertilizer and Organic-Inorganic Compound Liquid Fertilizer, Zhejiang Provincial Criteria DB33/699-2008, China.

[11] National Standards for Efficiency of Organic Fertilizers, NY525-2002, China.

[12] Demirel, B., Yenigun, O. and Turgut, T. (2005) Anaerobic Treatment of Dairy Wastewaters: A Review. Process Biochemistry, 40, 2583-2595.

https://doi.org/10.1016/j.procbio.2004.12.015

[13] Ushijima, K., Irie, M. and Ishikawa, T. (2005) A Preliminary Experiment on the Use of Sawdust Toilet at Ordinary Home in Japan. In: Wang, X.C. and Chen, R., Eds., Future of Urban Wastewater Systems-Decentralization and Reuse, China Architecture \& Building Press, Beijing, 71-78.

[14] Tani, M., Sakamoto, N., Kishimoto, T., et al. (2006) Utilization of Anaerobically Digested Dairy Slurry Combined with Other Wastes Following Application to Agricultural Land. International Congress Series, Vol. 1293, 331-334. https://doi.org/10.1016/j.ics.2006.03.013

[15] Kithome, M., Paul, J. and Bomke, A. (1999) Reducing Nitrogen Losses during Simulated Composting of Poultry Manure Using Adsorbents or Chemical Amendments. Journal of Environmental Quality, 28, 194-201. https://doi.org/10.2134/jeq1999.00472425002800010023x

[16] Milne, A.E., Glendining, M.J., Bellamy, P., Misselbrook, T., Gilhespy, S., Rivas Casado, M., Hulin, A., van Oijen, M. and Whitmore, A.P. (2018) Analysis of Uncertainties in the Estimates of Nitrous Oxide and Methane Emissions in the UK's Greenhouse Gas Inventory for Agriculture. Atmospheric Environment, 82, 94-105. https://doi.org/10.1016/j.atmosenv.2013.10.012

[17] Ziemba, C. and Peccia, J. (2011) Net Energy Production Associated with Pathogen Inactivation during Mesophilic and Thermophilic Anaerobic Digestion of Sewage Sludge. Water Research, 45, 4758-4768. https://doi.org/10.1016/j.watres.2011.06.014

[18] Sosnowski, P., Wieczorek, A. and Ledakowicz, S. (2003) Anaerobic Co-Digestion of Sewage Sludge and Organic Fraction of Municipal Solid Wastes. Advances in Environmental Research, 7, 609-616. https://doi.org/10.1016/S1093-0191(02)00049-7 